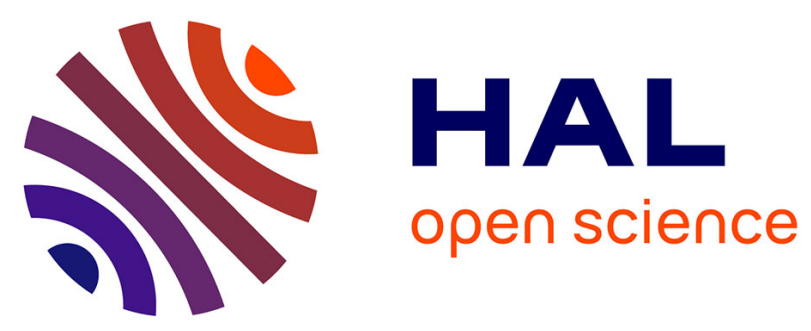

\title{
Endometrial cancer in elderly women: which disease, which surgical management? A systematic review of the literature
}

Charlotte Bourgin, Marine Saidani, Clotilde Poupon, Aurélie Cauchois, Fabrice Foucher, Jean Levêque, Vincent Lavoué

\section{To cite this version:}

Charlotte Bourgin, Marine Saidani, Clotilde Poupon, Aurélie Cauchois, Fabrice Foucher, et al.. Endometrial cancer in elderly women: which disease, which surgical management? A systematic review of the literature. EJSO - European Journal of Surgical Oncology, 2016, 42 (2), pp.166-175. 10.1016/j.ejso.2015.11.001 . hal-01231433

HAL Id: hal-01231433

https://hal-univ-rennes1.archives-ouvertes.fr/hal-01231433

Submitted on 7 Jan 2016

HAL is a multi-disciplinary open access archive for the deposit and dissemination of scientific research documents, whether they are published or not. The documents may come from teaching and research institutions in France or abroad, or from public or private research centers.
L'archive ouverte pluridisciplinaire HAL, est destinée au dépôt et à la diffusion de documents scientifiques de niveau recherche, publiés ou non, émanant des établissements d'enseignement et de recherche français ou étrangers, des laboratoires publics ou privés. 
1 Endometrial cancer in elderly women: which disease, which surgical management? A 2 systematic review of the literature

3

4 Charlotte Bourgin ${ }^{\mathrm{a}, \mathrm{b}}$, Marine Saidani ${ }^{\mathrm{a}, \mathrm{b}}$, Clotilde Poupon ${ }^{\mathrm{a}, \mathrm{b}}$, Aurelie Cauchois ${ }^{\mathrm{b}, \mathrm{c}}$, 5 Fabrice Foucher ${ }^{\mathrm{a}}$, J. Leveque ${ }^{\mathrm{a}, \mathrm{b}, \mathrm{d}}$, V. Lavoue ${ }^{\mathrm{a}, \mathrm{b}, \mathrm{d}}$

8

France.

c: Rennes University Hospital, Department of Pathology, Pontchaillou, 35000 RENNES,

France

d: INSERM ER440, Oncogenesis, Stress and Signaling (OSS), Rennes, France.

Corresponding author: Vincent Lavoue, MD, PhD, Vincent.lavoue@chu-rennes.fr. Rennes 35000 RENNES, France. University of Rennes 1, Faculty of Medicine, 2 rue Henri le Guilloux, 35000 Rennes, France. INSERM ER440, Oncogenesis, Stress and Signaling (OSS), Rennes, France.

All authors have no conflict of interest. 
26

27

28

29

30

31

32 55

\section{ABSTRACT}

Objective: Endometrial cancer primarily affects elderly women. The aim of the present literature review is to define the population of elderly women with this disease and to define the characteristics of this cancer in elderly people as well as its surgical treatment.

Materials and Methods: A systematic review of the English-language literature of the last 20 years indexed in the PubMed database.

Results: Endometrial cancer is more aggressive in elderly women. However, surgical staging performed in elderly patients is often not concomitant with the disease's aggressiveness in this group. Mini-invasive surgery is performed less often, for no obvious reason. Of note, oncogeriatric evaluation was not usually ruled out to determine the most appropriate surgical modality.

Conclusion: Studies are needed to evaluate surgical management of endometrial cancer in elderly women, notably with the aid of oncogeriatric scores to predict surgical morbidity.

Key words: elderly women, endometrial cancer, oncogeriatric scores, surgical approach

Authors have no conflict of interest. 


\section{INTRODUCTION}

48

49

50

51

52

53

54

55

56

57

58

59

60

Endometrial cancer is a disease primarily affecting elderly women: the mean age at diagnosis is 68 years (1). The current population is getting older, so the incidence of the disease and also its management are set to increase in the coming years. Anyone who takes an interest in this disease in the specific subpopulation formed by elderly women will notice it has features specific to this age group. The aim of the present literature review is to define which kind of endometrial cancer was found in elderly, how to define elderly and to focus on the surgical management performed and complications in elderly. In addition, we describe the feasibility and value of managing the disease in this age group using a mini-invasive approach (laparoscopic or robotic). 


\section{MATERIALS AND METHODS}

Inclusion criteria were studies that included adult femals with either age more than 65 years old and endometrial cancer with surgery. Exclusion criteria were patients with recurrent endometrial cancer, studies with no inclusion of women older than 65 years, duplicate data. Because of lack consensus of elderly woman definition in literature, authors researched also geriatric tools in order to define frailty. Inclusion criteria for this search were "oncologic score”.

The primary outcomes were rate of post-operative complications (morbidity and mortality), histo-pathological analysis of uterus and nodes and survival rate. The secondary outcome was described oncogeriatric scores nevertheless kind of cancer.

Original studies, meta-analyses and reviews published in English and French were considered. In case of duplicate publications from the same team, the most recent study was included. Case reports were excluded. Two investigators (CB and VL) independently extracted the data from the remaining studies. Finally, all the authors scrutinized relevant studies and a decision made on their inclusion in the review.

The bibliographic search was carried out for the period covering the last 20 years (January, 1995 to January, 2015). The following sources were explored:

- Medline: PubMed (the Internet portal of the National Library of Medicine)

http://www.ncbi.nlm.nih.gov/sites/entrez?db=pubmed

- Central Cochrane Library

- EmBase

- National Institute on Aging

http://www.nia.nih.gov/sites/default/files/

- INSEE: Institut National des Statistiques et des Etudes Economiques

http://www.insee.fr/fr/themes/document

The authors used various key words, alone or in combination, to produce maximum results during the literature search. The following key words were used: elderly women, older, frailty, laparoscopy, laparotomy, vaginal hysterectomy, surgery, recidive, specific survival, morbidity, endometrial carcinoma, endometrial cancer, oncogeriatric score. To minimize the possibility of duplication, all key fields of a particular study were downloaded including unique identifier (e.g. PMID), digital object identifier (DOI), clinical trial number (from 
92 www.clinicaltrials.gov), abstract and key words. The initial citations were then merged into 93 one file using the Endnote software and duplicate results were removed. The title of each 94 study was individually reviewed by designated authors to identify the studies addressing the research question. Thereafter, abstracts of selected studies were reviewed according to the 96 predefined inclusion and exclusion criteria and irrelevant studies were removed. Studies 97 meeting all inclusion and exclusion criteria were selected for full-text review and data 98 extraction.

99 


\section{RESULTS}

The electronic database literature search identified 25635 articles on endometrial cancer of which 2117 were about surgical staging and only 16 with detailed data about women older than 65 years old. Authors identified only two studies that assessed oncogeriatric score for surgery, of which only one deled with gynecologic oncology (2)(3). There is a lack of consensus in the definition of elderly and consequently there is a high heterogeneity of the published data to clearly review the subject.

\section{What is an elderly woman?}

In order to optimise the surgical management of elderly patients, it is important to better define what an elderly patient is, especially in surgery, and notably which of these elderly patients are at risk of complications.

There is no consensus in the current literature as regards the definition of "elderly woman", variously described as being over 63, 65, 70 or 75 years. Defining what constitutes an old person is a complex issue. One of the commonly used criteria is age, with the threshold age set at 65 years by the WHO (4) and the INSEE (5), and 75 years by the InCA (Institut National du Cancer). Another criterion, more socioeconomic, is to consider elderly as people who are no longer working. Hence, age is not a good way of predicting postoperative complications. Although not as straightforward to apply as age, vulnerability, frailty and dependence are better able to detect people to manage geriatrically and who are at risk of complications. Hence old age is not defined in relation to a specific age but rather as a state of functional incapacity, whether subjective or objective. The concept of frailty, today adopted by geriatricians, corresponds to a reduction in physiological reserves limiting the patient's capacity to respond to a stress and predisposing him/her to adverse events. It corresponds to a phenotype found in patients living in an institution, who have an excess risk of falls, hospitalisation, or other adverse events (6). As mentioned above, the population is getting older and life expectancy is increasing considerably. According to the INSEE, the life expectancy at 65 years for a woman is currently 23 years, while expectancy of life in "good health" at 65 years is 9 years (7). In relation to the topic we are interested in, surgery, the notion of good health is a very important one. 
Even though a definition of elderly in the field of surgery is lacking, it will be accepted that such a person has fewer physiological reserves to respond to the stress of a surgical procedure (anaesthesia, perioperative bleeding) or postoperative complications. So, in elderly people, more important than the rate of complications is that when a complication occurs postoperatively, it is less well tolerated and causes a chain reaction of other complications. Furthermore, elderly people may present complications specific to their age (e.g. confusion, falls, etc.), while so-called "classic" postoperative complications may have atypical presentations that the physician must be able to diagnose (8). In this context, new oncogeriatric scores are being used to better detect elderly people at risk of complications and those who would benefit from optimal medicosurgical treatment.

\section{Oncogeriatric scores}

The goal is to perform a comprehensive geriatric assessment (CGA), encompassing the somatic, functional and psychosocial domains, to provide an objective evaluation of the health status of the elderly person, so that a multidisciplinary care plan may be devised. The CGA uses several scores such as the MNA (Mini Nutritional Assessment), the ADL (Activity of Daily Living) and IADL (Instrumental Activity of Daily Living) that evaluate dependence, the MMSE (Mini Mental State Examination), the CIRS-G (Cumulative Illness Rating Scale for Geriatrics) evaluating comorbidities (9). The "timed get up and go test” (TUG) evaluates the risk of a fall, the VES-13 (Vulnerable Elders Scale) evaluates survival and decline and the GDS (Geriatric Depression Scale) evaluates depressive symptoms. A literature review involving 51 publications showed that frailty, nutritional status and comorbidities are predictive of all-cause mortality. Frailty is predictive of chemotherapy toxicity; cognitive impairment and a reduction in the ADL are predictive of chemotherapy discontinuation; reduction in the IADL is predictive of perioperative complications (10). The authors of the review express their reservations as to the validity of these tests, given that the studies are too heterogeneous to guide clinical decisions. Regardless of the issue of heterogeneity, the reference oncogeriatric evaluation test, the MGA (Multidimensional Geriatric Assessment), consisting of 7 items (MNA, TUG, ADL, IADL, MMSE, GDS and CIRS-G), takes a long time to administer, such that, despite the recommendations of the International Society of Geriatric Oncology (SIOG), level of use is very low. Currently, the scientific community believes that for a test to be acceptable, it must take about 10 minutes of the practitioner's 
time. With this in mind, the G8 tool was developed to identify patients who should undergo a geriatric evaluation. G8 consists of 8 items and its validity was recently assessed in a large, multicentre study (ONCODAGE), which showed that it takes an average of 5 minutes to complete it, it is more sensitive than VES-13 $(p=0.004)$ and that an abnormal score $(\leq 14 / 17)$ is predictive of 1-year survival ( $\mathrm{p}=0.0001)$. At the present time, G8 seems to be one of the best tools for detecting elderly patients who should undergo a geriatric evaluation (11). The current literature does not provide a specific score to evaluate perioperative risks in elderly people with cancer. Possibly because they are under-represented in clinical trials (12) (13), making their management even more difficult. Nevertheless, some studies have used existing oncogeriatric scores to evaluate this risk. Among these, a prospective study by the SIOG evaluated an extension of the CGA, the PACE (Preoperative Assessment in Elderly Cancer Patients), for its ability to assess the suitability of elderly cancer patients for surgery. This study used the MMS, ADL, IADL, GDS, BFI (Brief Fatigue Inventory), ECOG performance status (PS), ASA (American Society of Anesthesiology) scale and SIC (Satariano's Index of Comorbidities). Results showed that the IADL, fatigue and PS were associated with a 50\% increase in the relative risk of postoperative complications $(\mathrm{p}<0.05)$. On multivariate analysis, this study identified moderate to severe fatigue, the IADL and the PS as factors predictive of postoperative complications $(\mathrm{p}<0.05)$. Finally, deterioration of IADL and PS were associated with a longer hospital stay $(\mathrm{p}<0.05)(14)$. Independently of oncogeriatric scores but specifically in oncogynaecology, a retrospective Italian study evaluated perioperative morbidity and mortality in patients aged over 70 years as a function of the ASA score. It found a higher rate of postoperative complications in ASA III/IV patients than in ASA I/II patients ( $\mathrm{p} \leq 0.001)(15)$. There is no consensus regarding the definition of frailty. However Makary et al. established a frailty scale based on 5 criteria: weakness, weight loss, exhaustion, low physical activity and slow walking speed. This scale was tested in a prospective surgical study and was found to predict postoperative complications, length of hospital stay and placement in an institution of elderly people (2). In the specific domain of gynaecological surgical oncology, it has been established that preoperative frailty in elderly women is predictive of postoperative morbidity (postoperative complications and rehospitalisation within 30 days) (3). The score uses 5 variables that were previously validated by Fried et al. as defining frailty (6): weight loss, reduction in grip strength, exhaustion, low physical activity and slowing of walking speed. Each variable is rated as 0 or 1 . According to the frailty index, patients are classified as non-frail (0-1), intermediate-frail (2-3) or frail (4-5). Although this scale performs better than usual scores (ASA, ECOG, Charlson Comorbidity 
Index) (2) (16), it is still too time-consuming (approximately $20 \mathrm{~min}$ ). As the only existing tool for evaluating frailty in elderly women in the specific field of gynaecological oncological surgery, other studies are necessary in order to improve it and make it more practical.

\section{Characteristics of endometrial cancer in elderly women}

\section{Epidemiology}

In terms of incidence, endometrial cancer ranks number 4 among women, with 7,200 new cases per year in 2012 in France (InVS: Institut National de Veille Sanitaire) and it is the 5th most common cause of cancer mortality in women. It primarily occurs after the menopause, with a mean age of 68 years at diagnosis. The relative 5 -year survival rate is $76 \%$ overall, increasing to $95 \%$ for localised early stages. With the aging of population, a concomitant increase in the incidence of endometrial cancer can be observed: the probability of developing endometrial cancer at ages $40-59$ is $0.77 \%$, rising to $0.87 \%$ at ages $60-69$ and $1.24 \%$ at age $>70$ years (17). Hence, as women get older, they have a higher risk of developing endometrial cancer. It is interesting to know the National Institute on Aging estimates that in 2050 there will be 150 million people aged at least 65 years, representing $16 \%$ of the world population. Women will make up an increasing share of the population. People aged over 85 years ("the oldest old") represent $8 \%$ of the population aged over 65 years and up to $12 \%$ in more developed countries (4). The European Union has the highest percentage of people aged over 65 in the world: currently around $20 \%$ and forecast to increase to 30\% in 2060 (5). In line with aging of the female population, the incidence of endometrial cancer will increase. In this context, it seems useful to better characterise this disease in the specific population of elderly women.

\section{A more aggressive cancer}

Literature data show that endometrial cancer is more aggressive in elderly women, notably in terms of immunohistological profile and stage at which the disease is discovered. A retrospective American study involving 396 patients showed that, compared to younger patients, those aged over 65 years had significantly more of serous and clear cell subtypes (both histological type 2) associated with a poorer prognosis (18) than the endometrioid subtype $(\mathrm{p}=0.004)$ and also more histological grade 3 tumours $(\mathrm{p}=0.001)$. In this study, a 
stratified analysis by 4 age groups showed that patients aged over 75 years had serous carcinoma more often than patients aged below 45 years ( $22 \%$ vs $5 \%$; $\mathrm{p}=0.055)$, and more grade 3 tumours too ( $42 \%$ vs $16 \% \mathrm{p}=0.001$ ) (19). A more recent study evaluating biological markers of endometrial cancer aggressiveness, such as mutation of the p53 protein and decreased expression of the E-Cadherin protein, using 136 pathology slides, showed that advancing age is directly correlated with tumour stage $(\mathrm{r}=0.29$; $\mathrm{p}=0.0008)$, expression of a mutated p53 protein $(\mathrm{r}=0.25 ; \mathrm{p}=0.004)$ and is inversely correlated with expression of $\mathrm{E}$ Cadherin ( $r=-0.28 ; p=0.001)(20)$. An American study evaluating survival in a cohort of 243 elderly patients with endometrial cancer demonstrated a significantly higher proportion of serous carcinoma in patients aged over 63 years (28\% vs $15 \%$; p=0.002) (21). In parallel, an Italian study involving a prospective cohort of 108 patients with endometrial cancer and comparing laparoscopy in women over vs below 65 years found significantly more grade 3 tumours in the older group ( $33.3 \%$ vs $16.7 \%$; $\mathrm{p}=0.05$ ) (22). In this study, the tumour histological types were similar in both groups. A Canadian study comparing the management of endometrial cancer by robotic surgery in patients aged below 70 years, from 70 to 80 years and over 80 years found that both FIGO (International Federation of Gynecology and Obstetrics) stage and histological grade were more advanced in the older group ( $\mathrm{p}=0.023$ and $\mathrm{p}=0.002$, respectively) (23). In this study, there were no differences between the 3 age groups with regard to histological type 1 (endometrioid carcinoma) or 2 . Finally, a similar study by Vaknin et al. in 2010 in women aged over versus under 70 years found a higher rate of advanced FIGO stages (III and IV) in the older group (39\% vs 18.7\%; p<0.04) (24).

Hence, endometrial cancers affecting elderly women are more aggressive than those in younger patients, in terms of histological type (type 2), histological grade or FIGO stage at the time of diagnosis. The FIGO stage reflects the degree of advancement of the disease and it correlates directly with 5-year survival (25). The observation that disease is more advanced at time of diagnosis in elderly patients may be directly due to the fact that their tumours are inherently more aggressive. Alternatively, it may be due to delays in the management of elderly people or a delay on the part of the elderly person in seeking care, given that $20 \%$ of elderly people wait at least one year before consulting for clearly defined symptoms (26). 


\section{Which carcinogenesis?}

The difference in histology has been described for several years and it reflects two different pathways of carcinogenesis. The first, the "classic" pathway, starts with a hyperplastic precursor or an atypical hyperplastic component that, following oestrogenic stimulation, undergoes malignant transformation into endometrioid adenocarcinoma. These tumours are more frequent in younger, obese patients and are associated with a less advanced stage and grade. The other "alternative” pathway starts with an atrophic endometrium without oestrogenic stimulation and leads to development of serous cancers of the endometrium. This second type is more frequent in elderly women and is associated with a more advanced stage and grade, and also with poorer prognosis (27). These pathophysiological hypotheses are corroborated by literature data showing that BMI (Body Mass Index) is lower in elderly women with endometrial cancer. Lachance et al. divided their 396 patients into 3 age groups ( $<45$ years, 46-64 years, $>65$ years) and found an inverse relationship between age and BMI (40.3, 35.3, 31 respectively; $\mathrm{p}<0.001$ ) (19). In their retrospective study involving 338 patients with endometrial cancer aged over 50 years, Fleming et al. assessed age as a predictor of poor prognosis and similarly found that patients aged 50-69 had a mean BMI of 31 while those aged $>70$ had a mean BMI of 28 ( $\mathrm{p}=0.004)$ (28). The previously mentioned Canadian study in women with endometrial cancer found a mean BMI of 32.8 in patients $<70$ years, 30.2 in those aged $70-80$ and 21.5 for those aged $>80(p=0.0001)(23)$.

These morphological data are in favour of a carcinogenesis via the alternative pathway.

\section{Survival and recurrence}

The prognosis of endometrial cancer is grimmer in elderly patients. An American study from 2003 involving 405 patients with stage IB or II (former FIGO classification) endometrial cancer divided into 2 age groups, older and younger than 70 years, found a higher rate of recurrence in the older group ( $12 \%$ vs $5 \%$; $p=0.03$ ) (29). It also found a lower 5 -year cancer-specific survival rate in the older group ( $82 \%$ vs $95 \%$; $\mathrm{p}=0.03)$. On multivariate analysis, age over 70 years was also a significant factor predictive of poorer survival ( $\mathrm{p}=0.03$ ). Disease-specific survival was also less good in elderly women on both univariate and multivariate analysis ( $\mathrm{p}=0.02$ and 0.03 respectively). In their cohort of 243 patients, Jolly et al. (2006) found that the 5-year recurrence rate was higher in patients aged over 63 years 
compared to those aged below 63 years ( $32 \%$ vs $15 \%$; $p=0.02$ ), and that endometrial cancerspecific survival was worse in the older patients ( $75 \%$ vs $91 \%$; $\mathrm{p}=0.003$ ) (21). In 2013, an Italian study involving 124 elderly patients with endometrial cancer found that diseasespecific survival was lower in those aged over 80 years than in those aged below 80 years (56\% vs 83\%; p=0.008) (30). Only Fleming et al. did not find a significant difference in recurrence-free survival and disease-specific survival between patients aged over versus below 70 years (28).

Compared to younger patients, elderly patients with endometrial cancer have a higher recurrence rate and higher cancer-specific mortality.

One question remains unanswered by the literature: is there a difference in survival between the two age groups when histology is similar? If this is the case, is the (surgical and adjuvant) management of this cancer in elderly women not less optimal? (31) (32). In spite of elderly patients want their cancer to be treated as radically and completely as possible (33), this possible undertreatment could be explained by apprehension among medical practitioners about providing onerous treatments to this frailer patient group.

\section{What surgical management for elderly patients?}

Today, management of endometrial cancer is determined by the FIGO classification, which is based on the histology of the tumour, and lymph node involvement, obtained by lymphadenectomy and histopathological analysis. One question concerning elderly women with endometrial cancer is whether they receive optimal surgical management and by which approach: vaginal, laparotomic, or laparoscopic assisted by robot or not? This then leads to the question about the morbidity of surgical management in patients considered to be frailer. The bibliographic search identified 16 trials looking at the issue of surgical management of endometrial cancer in elderly people. Among these trials, 2 looked at the vaginal approach (30) (34), 2 at the laparotomic approach (19) (35), 8 at the laparoscopic approach (22) (36) (37) (38) (39) (40) (41) (42) and 4 at the robotic approach (23) (24) (43) (44). There were 5 retrospective studies (19) (34) (36) (39) (41), 7 prospective studies (22) (23) (24) (30) (35) (38) (44), 2 randomised studies (37) (40) and 2 retrospective surveys using a prospective database (42) (43). The age criterion varied among the studies: it was 63, 65, 70, 75 or 80 years. There were also differences from a methodological viewpoint: some of the studies compared two surgical approaches in the management of endometrial cancer in elderly 
women, while the others compared a single approach in elderly women versus younger women. The studies are summarised in Table 1.

\section{Perioperative data}

The first results collected concern perioperative data. The Susini study comparing the vaginal approach to laparotomy in patients aged over 70 years found a shorter operative time in the vaginal group ( $\mathrm{p}=0.01$ ) (34). In their study comparing laparotomy in patients aged over and under 70 years, Vaknin et al. did not find a difference in operative time between the age groups (35); neither did Lachance et al. in their study (19). Among the studies comparing laparoscopy and laparotomy in elderly women, only the study by Scribner et al., with a cutoff age of 65 years, found a shorter operative time in the laparotomy group ( $\mathrm{p}=0.0001)$ (36). The study by Bogani et al. did not find significant difference in operative time between the laparoscopic group and the laparotomic group (42). Studies comparing laparoscopy in elderly women with laparoscopy in younger women did not find significant difference in operative time between the two groups $(22,39,41)$. The study comparing laparotomy with robotic surgery found a shorter operative time in the laparotomy group ( $\mathrm{p}=0.009)$ (44). Vaknin et al., looking at management of endometrial cancer by robotic surgery, found a similar operative time in patients aged over and under 70 years (253 min vs $243 \mathrm{~min}$ ) (24); similar results were found by Lowe et al., who looked at the robotic approach in patients aged over and under 80 years (192 min vs $167 \mathrm{~min}$ ) (43) and by Zeng et al. in patients aged $<70$ years, 70-80 years and $>80$ years (23). Hence operative time for mini-invasive surgery is not longer in elderly women with endometrial cancer than in younger women. Only Scribner et al. found a longer operative time for laparoscopy compared with laparotomy (36) and Lavoué et al. for robotic surgery compared with laparotomy (44). This result is not against use of laparoscopy in this indication because the procedure is the same duration regardless of age and the study is quite old (2001). However, it does provide a reminder of the learning curve required by surgeons in order to perform this procedure by laparoscopy in a safe and sufficiently short manner (45). With regard to blood loss and transfusion rate, the study by Susini et al. found significantly less blood loss in the vaginal approach group than in the laparotomy group $(\mathrm{p}=0.01)$, but no significant difference between these two groups in terms of transfusion rate (34). Conversely, Scribner et al. found a higher transfusion rate in the laparoscopy group $(\mathrm{p}<0.0001)$ but no significant difference in blood loss between the laparoscopy group and the laparotomy group 
(36). The Lachance study comparing laparotomy in different age groups did not find a significant difference in blood loss (19); similarly the Vaknin study did not find a difference in terms of transfusion (35) in women aged over or under 70 years who underwent a laparotomy. The Bogani et al. study comparing laparoscopy with laparotomy in women aged over 75 years found significantly less blood loss in the laparoscopy group $(\mathrm{p}=0.005)$ but no difference between the 2 groups in terms of transfusions (42). However Ghezzi et al. report a lower rate of transfusions in the laparoscopy group $(\mathrm{p}<0.05)$ (38). Studies comparing laparoscopy in elderly women with laparoscopy in younger women did not find any significant differences between these two groups, in terms of either blood loss or transfusion rate $(22,39,41)$. Robotic surgery was associated with less blood loss when compared to laparotomy ( $\mathrm{p}=0.0001)(44)$, and there was no significant difference in blood loss between older and younger women (23) (24) (43). Hence, blood loss is equivalent in elderly women and younger women for a given surgical approach, and is higher for laparotomy compared with laparoscopy and robotic surgery (42) (44).

Studies comparing outcomes of laparoscopic and robotic modalities in elderly women versus younger women found a similar rate of conversion to laparotomy in both groups (22, 23, 39, 40, 41, 43). Only one study, the randomised Gynecologic Oncology Group (GOG) LAP2 Trial, found a higher rate of conversion for more advanced age (OR $=1.27$; 95\% CI: 1.14 to 1.42 per additional decade) (37). According to the literature, laparoscopic or robotic surgery in elderly patients is not associated with a higher rate of conversion to laparotomy. The comparative perioperative data are summarised in Table 2.

\section{Complications}

Other observations concern perioperative and postoperative complications. In this regard, Susini et al. did not find a significant difference in the number of severe complications that occurred in patients aged over 70 years who underwent a surgery by the vaginal route or who by laparotomy (19). None of the studies comparing laparoscopy with laparotomy in elderly women found a statistically significant difference in perioperative complications (36, $38,40,42)$. However, two studies have shown that there are significantly fewer postoperative complications in the laparoscopy group than in the laparotomy group $(15 / 33, p=0.002$ (36) and 5/24, p=0.05 (42) respectively). The other studies did not find a significant difference between the laparoscopy group and the laparotomy group in terms of perioperative 
complications ( $0 \%$ versus $5 \%$ (38) and $5.3 \%$ versus $4.3 \%$ (40)) or postoperative complications (6.3\% versus $9.5 \%$ (38) and $23.7 \%$ versus $17.4 \%(40)$ ).

Studies looking at outcomes in elderly versus younger women following laparoscopy did not find any significant differences between the two groups in terms of overall complications (6.4\% versus $2.7 \%$ ) (39), perioperative complications (4.2\% versus $1.7 \%$ ) or postoperative complications (25\% versus 23.3\%) (22). Similar findings were reported in a study comparing laparotomy outcomes in women aged over versus under 70 years in terms of overall complications (41.7\% vs $41.9 \%$ ) (35), and in a study comparing outcomes following robotic surgery (24). However, De Marzi et al., looking at laparotomy, found a higher rate of perioperative complications in women aged over 75 years (23\% vs 9\%, $\mathrm{p}=0.032$ ) (30). Interestingly, this significant difference vanishes if a cut-off age of 80 years is used (30). The study by Lowe et al. looking at robotic surgery in patients aged over versus under 80 years did not find more perioperative complications in the older women but it did find more postoperative complications in the older group ( $33 \%$ vs $13 \%$; $p=0.022$ ) (43). Similar findings were reported in another study on robotic surgery that divided patients into 3 age groups: the rate of perioperative complications was similar in the 3 groups $(0.5 \%$ vs $0 \%$ vs $3 \%)$, while there was a higher rate of grade III or IV (Clavien Dindo classification (46)) postoperative complications in patients aged over 80 years compared to those aged below 80 years $(10 \%$ vs $1 \%$ vs $0 \%$; $\mathrm{p}=0.0035$ ) (23). Lavoué et al., comparing the robotic approach with laparotomy, found significantly more Clavien Dindo grade I/II postoperative complications in the laparotomy group ( $17 \%$ vs $60 \%$; $\mathrm{p}<0.0001)$ but no difference was found with regard to grade III/IV complications (44). The comparative data concerning perioperative and postoperative complications are summarised in Table 3.

For a given surgical approach, elderly patients do not have more perioperative complications than younger patients. However, surgical management of endometrial cancers in this age group by laparotomy is associated with more morbidity than vaginal, laparoscopic or robotassisted modalities in terms of operative time, blood loss and perioperative complications. 


\section{Length of hospital stay}

Susini et al. found that the hospital stay was shorter in women operated on vaginally approach (6 days (d) vs 10 d; p=0.05 (34)). Studies comparing laparoscopy with laparotomy showed that the hospital stay was significantly shorter for patients who underwent laparoscopy ( 3 d versus $5.6 \mathrm{~d}$; $\mathrm{p}<0.0001$ (36); $2 \mathrm{~d}$ versus $6 \mathrm{~d}$; $\mathrm{p}<0.05$ (42); $2.5 \mathrm{~d}$ versus $7 \mathrm{~d}$; $\mathrm{p}<0.05$ (38)). The randomised GOG LAP2 trial (37) found that the proportion of patients requiring more than 2 days of hospitalisation after surgery was significantly lower in the laparoscopy group than in the laparotomy group (52\% versus $94 \%$; $\mathrm{p}<0.0001)$. In the two studies comparing laparotomy in elderly women of different ages, one of them did not find a significant difference in length of hospital stay in women between older vs younger than 70 years (35), while De Marzi et al. found a longer stay in women aged over 80 years (9.3 d vs $7.7 \mathrm{~d}$; $\mathrm{p}=0.036$ (30)). Studies comparing laparoscopy with the robotic approach in elderly women of different ages did not find a significant difference between the 2 or 3 age groups in terms of length of hospital stay (22, 23, 24, 39, 40, 43). In a comparison of robotic surgery with laparotomy, length of hospital stay was longer in women aged over 70 years who underwent a laparotomy (3.1 d vs $8 \mathrm{~d}$; $\mathrm{p}<0.0001$ (43)).

The use of mini-invasive surgery (laparoscopy and robotic) to manage endometrial cancers in elderly women is associated with a shorter hospital stay than laparotomy or the vaginal route; furthermore, the elderly women undergoing mini-invasive surgery are not hospitalized longer than younger women (Table 4).

Treatment of endometrial cancers is primarily surgical. Historically, surgery was performed by laparotomy, but in the last decade several studies have demonstrated the feasibility and advantages of laparoscopy and robotic surgery in the management of endometrial cancer in all patients (47) (48) and consequently have driven change in surgical practice in favour of laparoscopy and robotic surgery, the optimal surgical modalities with the lowest morbidity in this indication. Nevertheless, when it comes to surgical management of “elderly” patients with endometrial cancer, today’s medico-surgical teams have still not converted to the mini-invasive approach. Yet the present literature review shows that, in spite of the higher burden of comorbidities, elderly patients can also benefit from mini-invasive surgery to manage their endometrial cancer, in terms of blood loss, perioperative complications and length of hospital stay. 


\section{Surgical staging}

Surgical management of endometrial cancers notably includes pelvic and/or lumboaortic nodal staging. Among the previously cited studies, only the studies by Vaknin et al. comparing laparotomy or robotic surgery in patients older vs younger than 70 years found that significantly more lymph nodes were removed in patients below 70 years ( 4 vs $10.4 ; p<0.001$ (35) and 10 vs 13; $p=0.00613$ (24)). Studies comparing the number of lymph nodes removed by laparoscopy or laparotomy in elderly women with endometrial cancer aged over vs under 65 years (36) or 75 years (42), or by robotic surgery compared to laparotomy (44) or those comparing the number of lymph nodes removed by laparoscopy in women aged over vs below 65 years $(22,39)$ or 70 years $(41)$, similarly by laparotomy (19) or by robotic surgery $(23,43)$ did not find a significant difference in terms of the number of lymph nodes removed as function of patient age (Table 5). According to these studies, mini-invasive surgery appears to be a completely satisfactory technique for performing lymph node staging in endometrial cancers in elderly women.

From an oncology viewpoint, it can be seen that there is no significant difference in the number of lymph nodes removed as a function of age for a given surgical approach, except in the two studies by Vaknin et al. This could be explained by the fact that the surgeons in these two studies perform less-complete lymphadenectomies when patients are older, even though their disease is more aggressive. This gives rise to an important question not answered by the present literature review: independently of the lymph node number, do surgeons perform lymphadenectomy in elderly patients when this is recommended? It is known that in general oncological surgery, elderly patients are often undertreated (49) so it is pertinent to ask whether this is the case for endometrial cancer. Today, lymphadenectomy in the management of endometrial cancers is recommended or not as function of FIGO stage and tumour histology. Lymphadenectomy extends operative time, itself a morbidity factor in women aged over 80 years, given that a 30 -minute increase leads to a $17 \%$ increase in the complication rate (50) in this age group. Furthermore, it is associated with perioperative (vascular and neural) and postoperative (lymphoedema and neurological) risks. However, in view of the higher severity of endometrial cancer in elderly patients, it would be legitimate to perform lymphadenectomies more often. Further studies are required in order to determine whether nodal staging is performed or not in this age group and, if it is performed, to determine the associated morbidity, given that this information is not found in the literature. 


\section{5}

496

497

498

499

500

501

502

503

504

505

506

\section{CONCLUSION}

The incidence of endometrial cancer is increasing in line with the aging of the female population. In elderly women, this cancer is more aggressive yet often undertreated. This aggressiveness calls for optimal surgical management by the mini-invasive approach (including a lymphadenectomy when recommended) subject to oncogeriatric evaluation of frailty. Although frailty is better than age at predicting surgical morbidity, it is currently poorly defined - there is therefore a need to develop a short, quick score for predicting surgical morbidity.

Acknowledgments. VL has grants from "la Vannetaise". Acknowledgments are due to Tracey Wescott for editing manuscript. 
507

508 


\section{BIBLIOGRAPHY:}

1. ALD_30_GM_ENDOMETRE_INCA_HAS_WEB -

ald_30_gm_endometre_inca_has_web.pdf [Internet]. [cité 11 oct 2015]. Disponible sur: http://www.has-sante.fr/portail/upload/docs/application/pdf/201102/ald_30_gm_endometre_inca_has_web.pdf

2. Makary MA, Segev DL, Pronovost PJ, Syin D, Bandeen-Roche K, Patel P, et al. Frailty as a predictor of surgical outcomes in older patients. J Am Coll Surg. juin 2010;210(6):901-8.

3. Courtney-Brooks M, Tellawi AR, Scalici J, Duska LR, Jazaeri AA, Modesitt SC, et al. Frailty: an outcome predictor for elderly gynecologic oncology patients. Gynecol Oncol. juill 2012;126(1):20-4.

4. nia-who_report_booklet_oct-2011_a4_1-12-12_5.pdf [Internet]. [cité 27 févr 2014]. Disponible sur: http://www.nia.nih.gov/sites/default/files/nia-who_report_booklet_oct2011_a4_1-12-12_5.pdf

5. Insee - Population - Population par âge [Internet]. [cité 27 févr 2014]. Disponible sur: http://www.insee.fr/fr/themes/document.asp?ref_id=T11F036

6. Fried LP, Tangen CM, Walston J, Newman AB, Hirsch C, Gottdiener J, et al., Cardiovascular Health Study Collaborative Research Group. Frailty in older adults: evidence for a phenotype. J Gerontol A Biol Sci Med Sci. mars 2001;56(3):M146-56.

7. C256.pdf [Internet]. [cité 10 janv 2015]. Disponible sur: http://www.credoc.fr/pdf/Rech/C256.pdf

8. Common perioperative Complications in Older Patients [Internet]. [cité 28 mars 2014]. Disponible sur: http://www.springer.com/cda/content/document/cda_downloaddocument/978144196998 9-c29.pdf?SGWID=0-0-45-1152939-p174128180

9. Terret C, Droz J-P. [Definition and outline on geriatric oncology]. Prog En Urol J Assoc Fr Urol Société Fr Urol. nov 2009;19 Suppl 3:S75-9.

10. Hamaker ME, Vos AG, Smorenburg CH, de Rooij SE, van Munster BC. The value of geriatric assessments in predicting treatment tolerance and all-cause mortality in older patients with cancer. The oncologist. 2012;17(11):1439-49.

11. Soubeyran P, Bellera C, Goyard J, Heitz D, Curé H, Rousselot H, et al. Screening for Vulnerability in Older Cancer Patients: The ONCODAGE Prospective Multicenter Cohort Study. PloS One. 2014;9(12):e115060. 
12. Mitka M. Too few older patients in cancer trials: experts say disparity affects research results and care. JAMA. 2 juill 2003;290(1):27-8.

13. Lewis JH, Kilgore ML, Goldman DP, Trimble EL, Kaplan R, Montello MJ, et al. Participation of patients 65 years of age or older in cancer clinical trials. J Clin Oncol Off J Am Soc Clin Oncol. 1 avr 2003;21(7):1383-9.

14. Audisio RA, Pope D, Ramesh HSJ, Gennari R, van Leeuwen BL, West C, et al. with PACE participants. Shall we operate? Preoperative assessment in elderly cancer patients (PACE) can help. A SIOG surgical task force prospective study. Crit Rev Oncol Hematol. févr 2008;65(2):156-63.

15. Giannice R, Foti E, Poerio A, Marana E, Mancuso S, Scambia G. Perioperative morbidity and mortality in elderly gynecological oncological patients ( $>/=70$ Years) by the American Society of Anesthesiologists physical status classes. Ann Surg Oncol. févr 2004;11(2):219-25.

16. Revenig LM, Canter DJ, Taylor MD, Tai C, Sweeney JF, Sarmiento JM, et al. Too frail for surgery? Initial results of a large multidisciplinary prospective study examining preoperative variables predictive of poor surgical outcomes. J Am Coll Surg. oct 2013;217(4):665-70.e1.

17. Siegel R, Naishadham D, Jemal A. Cancer statistics, 2013. CA Cancer J Clin. janv 2013;63(1):11-30.

18. Park JY, Nam J-H, Kim Y-T, Kim Y-M, Kim J-H, Kim D-Y, et al. Poor prognosis of uterine serous carcinoma compared with grade 3 endometrioid carcinoma in early stage patients. Virchows Arch Int J Pathol. mars 2013;462(3):289-96.

19. Lachance JA, Everett EN, Greer B, Mandel L, Swisher E, Tamimi H, et al. The effect of age on clinical/pathologic features, surgical morbidity, and outcome in patients with endometrial cancer. Gynecol Oncol. juin 2006;101(3):470-5.

20. Gonzalez-Rodilla I, Boix M, Verna V, Muñoz AB, Estévez J, Jubete $Y$, et al. Patient age and biological aggressiveness of endometrial carcinoma. Anticancer Res. mai 2012;32(5):1817-20.

21. Jolly S, Vargas CE, Kumar T, Weiner SA, Brabbins DS, Chen PY, et al. The impact of age on long-term outcome in patients with endometrial cancer treated with postoperative radiation. Gynecol Oncol. oct 2006;103(1):87-93.

22. Siesto G, Uccella S, Ghezzi F, Cromi A, Zefiro F, Serati M, et al. Surgical and survival outcomes in older women with endometrial cancer treated by laparoscopy. Menopause $\mathrm{N} Y$ N. juin 2010;17(3):539-44. 
23. Zeng XZ, Lavoue V, Lau S, Press JZ, Abitbol J, Gotlieb R, et al. Outcome of Robotic Surgery for Endometrial Cancer as a Function of Patient Age. Int J Gynecol Cancer Off J Int Gynecol Cancer Soc. 26 févr 2015;

24. Vaknin Z, Perri T, Lau S, Deland C, Drummond N, Rosberger Z, et al. Outcome and quality of life in a prospective cohort of the first 100 robotic surgeries for endometrial cancer, with focus on elderly patients. Int J Gynecol Cancer Off J Int Gynecol Cancer Soc. nov 2010;20(8):1367-73.

25. Creasman W. Revised FIGO staging for carcinoma of the endometrium. Int J Gynaecol Obstet Off Organ Int Fed Gynaecol Obstet. mai 2009;105(2):109.

26. Le diagnostic [Internet]. Fondation ARC pour la recherche sur le cancer. [cité 14 févr 2015]. Disponible sur: http://www.fondation-arc.org/Le-cancer-chez-la-personneagee/oncogeriatrie-le-diagnostic.html

27. Lax SF. [Dualistic model of molecular pathogenesis in endometrial carcinoma]. Zentralblatt Für Gynäkol. janv 2002;124(1):10-6.

28. Fleming ND, Lentz SE, Cass I, Li AJ, Karlan BY, Walsh CS. Is older age a poor prognostic factor in stage I and II endometrioid endometrial adenocarcinoma? Gynecol Oncol. févr 2011;120(2):189-92.

29. Alektiar KM, Venkatraman E, Abu-Rustum N, Barakat RR. Is endometrial carcinoma intrinsically more aggressive in elderly patients? Cancer. 1 déc 2003;98(11):2368-77.

30. De Marzi P, Ottolina J, Mangili G, Rabaiotti E, Ferrari D, Viganò R, et al. Surgical treatment of elderly patients with endometrial cancer ( $\geq 65$ years). J Geriatr Oncol. oct 2013;4(4):368-73.

31. Ouldamer L, Duquesne M, Arbion F, Barillot I, Marret H, Body G. Impact de la prise en charge thérapeutique sur la survie chez les femmes très âgées avec cancer de l'endomètre. Gynécologie Obstétrique Fertil. déc 2012;40(12):759-64.

32. Ahmed A, Zamba G, DeGeest K, Lynch CF. The impact of surgery on survival of elderly women with endometrial cancer in the SEER program from 1992-2002. Gynecol Oncol. 1 oct 2008;111(1):35-40.

33. Nordin AJ, Chinn DJ, Moloney I, Naik R, de Barros Lopes A, Monaghan JM. Do elderly cancer patients care about cure? Attitudes to radical gynecologic oncology surgery in the elderly. Gynecol Oncol. juin 2001;81(3):447-55.

34. Susini T, Massi G, Amunni G, Carriero C, Marchionni M, Taddei G, et al. Vaginal hysterectomy and abdominal hysterectomy for treatment of endometrial cancer in the elderly. Gynecol Oncol. févr 2005;96(2):362-7. 
35. Vaknin Z, Ben-Ami I, Schneider D, Pansky M, Halperin R. A comparison of perioperative morbidity, perioperative mortality, and disease-specific survival in elderly women (>or=70 years) versus younger women (<70 years) with endometrioid endometrial cancer. Int J Gynecol Cancer Off J Int Gynecol Cancer Soc. juill 2009;19(5):879-83.

36. Scribner Jr. DR, Walker JL, Johnson GA, McMeekin SD, Gold MA, Mannel RS. Surgical Management of Early-Stage Endometrial Cancer in the Elderly: Is Laparoscopy Feasible? Gynecol Oncol. déc 2001;83(3):563-8.

37. Walker JL, Piedmonte MR, Spirtos NM, Eisenkop SM, Schlaerth JB, Mannel RS, et al. Laparoscopy compared with laparotomy for comprehensive surgical staging of uterine cancer: Gynecologic Oncology Group Study LAP2. J Clin Oncol Off J Am Soc Clin Oncol. 10 nov 2009;27(32):5331-6.

38. Ghezzi F, Cromi A, Siesto G, Serati M, Bogani G, Sturla D, et al. Use of laparoscopy in older women undergoing gynecologic procedures: is it time to overcome initial concerns? Menopause N Y N. févr 2010;17(1):96-103.

39. Frey MK, Ihnow SB, Worley MJ Jr, Heyman KP, Kessler R, Slomovitz BM, et al. Minimally invasive staging of endometrial cancer is feasible and safe in elderly women. J Minim Invasive Gynecol. avr 2011;18(2):200-4.

40. Bijen CBM, de Bock GH, Vermeulen KM, Arts HJG, ter Brugge HG, van der Sijde R, et al. Laparoscopic hysterectomy is preferred over laparotomy in early endometrial cancer patients, however not cost effective in the very obese. Eur J Cancer Oxf Engl 1990. sept 2011;47(14):2158-65.

41. Perrone AM, Di Marcoberardino B, Rossi M, Pozzati F, Pellegrini A, Procaccini M, et al. Laparoscopic versus laparotomic approach to endometrial cancer. Eur J Gynaecol Oncol. 2012;33(4):376-81.

42. Bogani G, Cromi A, Uccella S, Serati M, Casarin J, Mariani A, et al. Laparoscopic staging in women older than 75 years with early-stage endometrial cancer: comparison with open surgical operation. Menopause N Y N. 27 janv 2014;

43. Lowe MP, Kumar S, Johnson PR, Kamelle SA, Chamberlain DH, Tillmanns TD. Robotic surgical management of endometrial cancer in octogenarians and nonagenarians: analysis of perioperative outcomes and review of the literature. J Robot Surg. 11 juin 2010;4(2):109-15.

44. Lavoue V, Zeng X, Lau S, Press JZ, Abitbol J, Gotlieb R, et al. Impact of robotics on the outcome of elderly patients with endometrial cancer. Gynecol Oncol. juin 2014;133(3):556-62. 
643 45. Tahmasbi Rad M, Wallwiener M, Rom J, Sohn C, Eichbaum M. Learning curve for 644 laparoscopic staging of early and locally advanced cervical and endometrial cancer. Arch 645 Gynecol Obstet. sept 2013;288(3):635-42.

46. Dindo D, Demartines N, Clavien P-A. Classification of surgical complications: a new proposal with evaluation in a cohort of 6336 patients and results of a survey. Ann Surg. août 2004;240(2):205-13.

47. Hauspy J, Jiménez W, Rosen B, Gotlieb WH, Fung-Kee-Fung M, Plante M. Laparoscopic surgery for endometrial cancer: a review. J Obstet Gynaecol Can JOGC J Obstétrique Gynécologie Can JOGC. juin 2010;32(6):570-9.

48. Holloway RW, Ahmad S, DeNardis SA, Peterson LB, Sultana N, Bigsby GE, et al. Robotic-assisted laparoscopic hysterectomy and lymphadenectomy for endometrial cancer: Analysis of surgical performance. Gynecol Oncol. 1 déc 2009;115(3):447-52.

49. Monson K, Litvak DA, Bold RJ. Surgery in the aged population: Surgical oncology. Arch Surg. 1 oct 2003;138(10):1061-7.

50. Turrentine FE, Wang $\mathrm{H}$, Simpson VB, Jones RS. Surgical risk factors, morbidity, and mortality in elderly patients. J Am Coll Surg. déc 2006;203(6):865-77. 
661 Table 1: Studies looking at management of endometrial cancer in elderly women

\begin{tabular}{|c|c|c|c|c|c|}
\hline Authors & Year & Study type & $\begin{array}{c}\text { Number of } \\
\text { patients }\end{array}$ & Age (years) & Comparison \\
\hline Scribner et al. ${ }^{36}$ & 2001 & Retrospective & 125 & $\geq 65$ & $\begin{array}{c}\text { Laparotomy vs } \\
\text { laparoscopy }\end{array}$ \\
\hline Susini et al. ${ }^{34}$ & 2004 & Retrospective & 171 & $\geq 70$ & Vaginal vs \\
\hline Lachance et al. ${ }^{19}$ & 2006 & Retrospective & 396 & $\geq 65$ & Age \\
\hline Vaknin et al. ${ }^{35}$ & 2009 & Prospective & 115 & $\geq 70$ & Age \\
\hline Walker et al. ${ }^{37}$ & 2009 & $\begin{array}{l}\text { Randomized } \\
\text { study }\end{array}$ & 1682 & & $\begin{array}{c}\text { Laparotomy vs } \\
\text { laparoscopy }\end{array}$ \\
\hline Ghezzi et al. ${ }^{38}$ & 2010 & Prospective & 231 & $\geq 70$ & $\begin{array}{c}\text { Laparotomy vs } \\
\text { laparoscopy }\end{array}$ \\
\hline Siesto et al. ${ }^{22}$ & 2010 & Prospective & 108 & $\geq 65$ & Age \\
\hline Vaknin et al. ${ }^{24}$ & 2010 & Prospective & 100 & $\geq 70$ & Age \\
\hline Lowe et al. ${ }^{43}$ & 2010 & Retrospective & 395 & $\geq 80$ & Age \\
\hline Frey et al. ${ }^{39}$ & 2011 & Retrospective & 129 & $\geq 65$ & Age \\
\hline Bijen et al. ${ }^{40}$ & & $\begin{array}{c}\text { Randomized } \\
\text { study }\end{array}$ & 238 & $\geq 70$ & $\begin{array}{c}\text { Laparotomy vs } \\
\text { laparoscopy }\end{array}$ \\
\hline Perrone et al. ${ }^{41}$ & 2012 & Retrospective & 210 & $\geq 70$ & $\begin{array}{c}\text { Laparotomy vs } \\
\text { laparoscopy }\end{array}$ \\
\hline De Marzi et al. ${ }^{30}$ & 2013 & Prospective & 124 & $\geq 75$ & Age \\
\hline Zeng et al. ${ }^{23}$ & 2013 & Prospective & 373 & $\geq 70 ; \geq 80$ & Age \\
\hline Bogani et al. ${ }^{42}$ & 2014 & Retrospective & 125 & $\geq 75$ & $\begin{array}{c}\text { Laparotomy vs } \\
\text { laparoscopy }\end{array}$ \\
\hline Lavoue et al. ${ }^{44}$ & 2014 & Prospective & 163 & $\geq 70$ & $\begin{array}{c}\text { Laparotomy vs } \\
\text { Robot }\end{array}$ \\
\hline
\end{tabular}


664 Table 2: Perioperative data from studies looking at surgical management of endometrial cancer in elderly women

\begin{tabular}{|c|c|c|c|c|c|}
\hline Study & Type & $\begin{array}{l}\text { Operative } \\
\text { time (min) }\end{array}$ & $\begin{array}{l}\text { Blood loss } \\
\text { (ml) }\end{array}$ & $\begin{array}{c}\text { Transfusions } \\
\text { (\%) }\end{array}$ & $\begin{array}{c}\text { Conversion } \\
(\%)\end{array}$ \\
\hline Susini et al.$^{34}$ & $\begin{array}{l}\text { Vag/Ltm } \\
\geq 70\end{array}$ & $\begin{array}{l}46 / 115 \\
p=0.01\end{array}$ & $\begin{array}{c}210 / 400 \\
p=0.01\end{array}$ & $\begin{array}{l}7 / 5 \\
\text { NS }\end{array}$ & $\mathrm{N} / \mathrm{P}$ \\
\hline Vaknin et al.$^{35}$ & $\begin{array}{l}\mathrm{Ltm} \\
\geq 70 /<70\end{array}$ & $\begin{array}{c}141 / 132 \\
\text { NS }\end{array}$ & $\mathrm{N} / \mathrm{P}$ & $\begin{array}{l}10 / 4 \\
\text { NS }\end{array}$ & $\mathrm{N} / \mathrm{P}$ \\
\hline Lachance et al. ${ }^{19}$ & $\begin{array}{l}\mathrm{Ltm} \\
\geq 65 /<65\end{array}$ & $\begin{array}{c}176 / 185 \\
\text { NS }\end{array}$ & $\begin{array}{c}384 / 450 \\
\text { NS }\end{array}$ & $\mathrm{N} / \mathrm{P}$ & $\mathrm{N} / \mathrm{P}$ \\
\hline Scribner et al. ${ }^{36}$ & $\begin{array}{l}\text { Lscp / Ltm } \\
\geq 65\end{array}$ & $236 / 148 \mathrm{p}=0.0001$ & $\begin{array}{c}\text { 298/336 } \\
\text { NS }\end{array}$ & $\begin{array}{c}19.2 / 2.2 \\
\mathrm{p}<0.0001\end{array}$ & 22 \\
\hline Bogani et al. ${ }^{42}$ & $\begin{array}{l}\text { Lscp / Ltm } \\
\geq 75\end{array}$ & $\begin{array}{l}120 / 90 \\
\text { NS }\end{array}$ & $\begin{array}{l}100 / 175 \\
p=0.005\end{array}$ & $\begin{array}{l}2 / 6 \\
\text { NS }\end{array}$ & 2 \\
\hline Ghezzi et al. ${ }^{38}$ & $\begin{array}{l}\text { Lscp / Ltm } \\
\geq 70\end{array}$ & $\mathrm{~N} / \mathrm{P}$ & $\mathrm{N} / \mathrm{P}$ & $\begin{array}{l}4.2 / 26.5 \\
\mathrm{p}<0.05\end{array}$ & $\mathrm{~N} / \mathrm{P}$ \\
\hline Frey et al. ${ }^{39}$ & $\begin{array}{l}\text { Lscp } \\
\geq 65 /<65\end{array}$ & $\begin{array}{c}229 / 223 \\
\text { NS }\end{array}$ & $\begin{array}{c}165 / 166 \\
\text { NS }\end{array}$ & $\begin{array}{l}3.2 / 2.7 \\
\text { NS }\end{array}$ & $0 / 0$ \\
\hline Siesto et al. ${ }^{22}$ & $\begin{array}{l}\text { Lscp } \\
\geq 65 /<65\end{array}$ & $\begin{array}{l}182 / 175 \\
\text { NS }\end{array}$ & $\begin{array}{l}100 / 100 \\
\text { NS }\end{array}$ & $\begin{array}{l}4.2 / 1.7 \\
\text { NS }\end{array}$ & $0 / 0$ \\
\hline Bijen et al. ${ }^{40}$ & $\begin{array}{l}\text { Lscp } \\
\geq 70 /<70\end{array}$ & $\mathrm{~N} / \mathrm{P}$ & $\mathrm{N} / \mathrm{P}$ & $\mathrm{N} / \mathrm{P}$ & $\begin{array}{l}10.5 / 10.9 \\
\text { NS }\end{array}$ \\
\hline Perrone et al. ${ }^{41}$ & $\begin{array}{l}\text { Lscp } \\
\geq 70 /<70\end{array}$ & $\begin{array}{c}267 / 286 \\
\text { NS }\end{array}$ & $\mathrm{N} / \mathrm{P}$ & $\mathrm{N} / \mathrm{P}$ & $\begin{array}{l}2 / 4 \\
\text { NS }\end{array}$ \\
\hline Vaknin et al. ${ }^{24}$ & $\begin{array}{l}\text { Rob } \\
\geq 70 /<70\end{array}$ & $\begin{array}{l}243 / 253 \\
\text { NS }\end{array}$ & $\begin{array}{c}83 / 81 \\
\text { NS }\end{array}$ & N/P & $\mathrm{N} / \mathrm{P}$ \\
\hline Lowe et al. ${ }^{43}$ & $\begin{array}{l}\text { Rob } \\
\geq 80 /<80\end{array}$ & $\begin{array}{c}192 / 167 \\
\text { NS }\end{array}$ & $\begin{array}{l}50 / 50 \\
\text { NS }\end{array}$ & $\mathrm{N} / \mathrm{P}$ & $\begin{array}{c}3.7 / 7 \\
\mathrm{NS}\end{array}$ \\
\hline Zeng et al. ${ }^{23}$ & $\begin{array}{l}\text { Rob } \\
\geq 80 / 80 \text { to } 70 /<70\end{array}$ & $\begin{array}{c}237 / 249 / 241 \\
\text { NS }\end{array}$ & $\begin{array}{c}88 / 69 / 78 \\
\text { NS }\end{array}$ & $\mathrm{N} / \mathrm{P}$ & $\begin{array}{l}1 / 1 / 4 \\
\text { NS }\end{array}$ \\
\hline Lavoue et al. ${ }^{44}$ & $\begin{array}{l}\text { Rob/Ltm } \\
\geq 70\end{array}$ & $\begin{array}{c}244.2 / 217.7 \\
p=0.09\end{array}$ & $\begin{array}{c}74.8 / 234 \\
p=0.0001\end{array}$ & $\mathrm{~N} / \mathrm{P}$ & $\mathrm{N} / \mathrm{P}$ \\
\hline
\end{tabular}


670

Table 3: Rate of complications foun
endometrial cancer in elderly women

\begin{tabular}{|c|c|c|c|c|}
\hline Study & Туре & $\begin{array}{c}\text { Perioperative } \\
\text { complications } \\
(\%)\end{array}$ & $\begin{array}{c}\text { Postoperative } \\
\text { complications } \\
(\%)\end{array}$ & $\begin{array}{c}\text { Overall } \\
\text { complications }\end{array}$ \\
\hline Susini et al. ${ }^{34}$ & $\begin{array}{l}\text { Vag/Ltm } \\
\geq 70\end{array}$ & $\mathrm{~N} / \mathrm{P}$ & $\mathrm{N} / \mathrm{P}$ & $\begin{array}{l}5.4 / 7 \\
\text { NS }\end{array}$ \\
\hline Scribner et al. ${ }^{36}$ & $\begin{array}{l}\text { Lscp / Ltm } \\
\geq 65\end{array}$ & $7 / 0$ & $\begin{array}{c}15 / 33 \\
p=0.002\end{array}$ & $\mathrm{~N} / \mathrm{P}$ \\
\hline Bogani et al. ${ }^{42}$ & $\begin{array}{l}\text { Lscp / Ltm } \\
\geq 75\end{array}$ & $\begin{array}{l}3 / 2 \\
\mathrm{NS}\end{array}$ & $\begin{array}{c}5 / 24 \\
p=0.05\end{array}$ & $\mathrm{~N} / \mathrm{P}$ \\
\hline Ghezzi et al. ${ }^{38}$ & $\begin{array}{l}\text { Lscp / Ltm } \\
\geq 70\end{array}$ & $\begin{array}{l}0 / 5 \\
\text { NS }\end{array}$ & $\begin{array}{l}6.3 / 9.5 \\
\text { NS }\end{array}$ & $\mathrm{N} / \mathrm{P}$ \\
\hline Bijen et al. ${ }^{40}$ & $\begin{array}{l}\text { Lscp / Ltm } \\
\geq 70\end{array}$ & $\begin{array}{c}5.3 / 4.3 \\
\mathrm{~N} / \mathrm{T}\end{array}$ & $\begin{array}{c}23.7 / 17.4 \\
\text { N/T }\end{array}$ & $\begin{array}{c}28.9 / 21.7 \\
\mathrm{~N} / \mathrm{T}\end{array}$ \\
\hline Frey et al. ${ }^{39}$ & $\begin{array}{l}\text { Lscp } \\
\geq 65 / \leq 65\end{array}$ & $\mathrm{~N} / \mathrm{P}$ & $\mathrm{N} / \mathrm{P}$ & $\begin{array}{c}6.4 / 2.7 \\
\text { NS }\end{array}$ \\
\hline Siesto et al. ${ }^{22}$ & $\begin{array}{l}\text { Lscp } \\
\geq 65 / \leq 65\end{array}$ & $\begin{array}{l}4.2 / 1.7 \\
\text { NS }\end{array}$ & $\begin{array}{c}25 / 23.3 \\
\text { NS }\end{array}$ & $\mathrm{N} / \mathrm{P}$ \\
\hline Vaknin et al. ${ }^{35}$ & $\begin{array}{l}\text { Ltm } \\
\geq 70 /<70\end{array}$ & $\mathrm{~N} / \mathrm{P}$ & $\mathrm{N} / \mathrm{P}$ & $\begin{array}{c}41.7 / 41.9 \\
\text { NS }\end{array}$ \\
\hline DeMarzi et al. ${ }^{30}$ & $\begin{array}{l}\text { Ltm } \\
\geq 75 /<75\end{array}$ & $\mathrm{~N} / \mathrm{P}$ & $\mathrm{N} / \mathrm{P}$ & $\begin{array}{c}23 / 9 \\
p=0.032\end{array}$ \\
\hline Vaknin et al. ${ }^{24}$ & $\begin{array}{l}\text { Rob } \\
\geq 70 /<70\end{array}$ & $\begin{array}{l}0 / 2 \\
\text { NS }\end{array}$ & $\begin{array}{c}12 / 5^{*} \\
\text { NS }\end{array}$ & $\mathrm{N} / \mathrm{P}$ \\
\hline Lowe et al. ${ }^{43}$ & $\begin{array}{l}\text { Rob } \\
\geq 80 /<80\end{array}$ & $\begin{array}{c}7.4 / 5.1 \\
\text { NS }\end{array}$ & $\begin{array}{c}33 / 13 \\
p=0.022\end{array}$ & $\mathrm{~N} / \mathrm{P}$ \\
\hline Zeng et al. ${ }^{23}$ & $\begin{array}{l}\text { Rob } \\
\geq 80 / 80 \text { to }\end{array}$ & $\begin{array}{c}\text { 3/0/0.5 } \\
\text { NS }\end{array}$ & $\begin{array}{c}10 / 1 / 0^{*} \\
p=0.0035\end{array}$ & $\mathrm{~N} / \mathrm{P}$ \\
\hline Lavoue et al. ${ }^{44}$ & $\begin{array}{l}\text { Rob/Ltm } \\
\geq 70\end{array}$ & $\mathrm{~N} / \mathrm{P}$ & $\begin{array}{c}17 / 60 * * \\
\mathrm{p}<0.0001\end{array}$ & $\mathrm{~N} / \mathrm{P}$ \\
\hline
\end{tabular}

Vag: vaginal; Ltm: Laparotomy; Lscp: Laparoscopy; Rob: Robotic; NS: non-significant; N/T: not tested; N/P: not provided; * grade I/II or ** grade III/IV complications of the Clavien Dindo classification 
678 679

\begin{tabular}{|c|c|c|c|}
\hline Study & Type & $\begin{array}{c}\text { Length of hospital } \\
\text { stay (d) }\end{array}$ & $p$ value \\
\hline Susini et al. ${ }^{34}$ & $\mathrm{Vag} / \mathrm{Ltm} \geq 70$ & $6 / 10$ & 0.05 \\
\hline Scribner et al. ${ }^{36}$ & Lscp / Ltm $\geq 65$ & $3 / 5.6$ & $\mathrm{p}<0.0001$ \\
\hline Bogani et al. ${ }^{48}$ & Lscp / Ltm $\geq 75$ & $2 / 6$ & $\mathrm{p}<0.0001$ \\
\hline Ghezzi et al. ${ }^{38}$ & $\mathrm{Lscp} / \mathrm{Ltm} \geq 70$ & $2.5 / 7$ & $\mathrm{p}<0.05$ \\
\hline Frey et al. ${ }^{39}$ & Lscp $\geq 65 / \leq 65$ & 2.9/1.7 & NS \\
\hline Siesto et al. ${ }^{22}$ & Lscp $\geq 65 / \leq 65$ & & NS \\
\hline Perrone et al. ${ }^{41}$ & Lscp $\geq 70 /<70$ & $3.6 / 3.6$ & NS \\
\hline Vaknin et al. ${ }^{35}$ & $\mathrm{Ltm} \geq 70 /<70$ & $5.4 / 4.9$ & NS \\
\hline DeMarzi et al. ${ }^{30}$ & $\mathrm{Ltm} \geq 80 /<80$ & $9.3 / 7.7$ & $p=0.036$ \\
\hline Vaknin et al. ${ }^{24}$ & Rob $\geq 70 /<70$ & $2 / 1$ & NS \\
\hline Lowe et al. ${ }^{43}$ & Rob $\geq 80 /<80$ & $1 / 1$ & NS \\
\hline Zeng et al. ${ }^{23}$ & Rob $\geq 80 / 80$ to $70 /<70$ & $2 / 1 / 1$ & NS \\
\hline Lavoue et al. ${ }^{44}$ & $\mathrm{Rob} / \mathrm{Ltm} \geq 70$ & $3.1 / 8$ & $\mathrm{p}<0.0001$ \\
\hline
\end{tabular}

Vag: vaginal; Lscp: Laparoscopy; Ltm: Laparotomy; Rob: Robotic; d: days; NS: non681 significant.

Table 4: Length of hospital stay in studies looking at surgical management of endometrial cancer in elderly women
682

683

684

685

686

687

85

86 87

82

\section{3}


688

\begin{tabular}{|c|c|c|c|c|c|}
\hline Study & Type & $\begin{array}{l}\text { No of pelvic } \\
\text { lymph nodes }\end{array}$ & $\begin{array}{l}\text { No of lombo- } \\
\text { aortic lymph } \\
\quad \text { nodes }\end{array}$ & $\begin{array}{c}\text { Total No of } \\
\text { lymph } \\
\text { nodes }\end{array}$ & $p$ value \\
\hline Scribner et al. ${ }^{36}$ & Lscp / Ltm $\geq 65$ & $17.8 / 19.1$ & $6.6 / 5.2$ & $\mathrm{~N} / \mathrm{P}$ & NS \\
\hline Bogani et al. ${ }^{42}$ & Lscp / Ltm $\geq 75$ & $\mathrm{~N} / \mathrm{P}$ & $\mathrm{N} / \mathrm{P}$ & $14 / 13$ & NS \\
\hline Frey et al. ${ }^{39}$ & Lscp $\geq 65 / \leq 65$ & $\mathrm{~N} / \mathrm{P}$ & $\mathrm{N} / \mathrm{P}$ & 19.2/17.3 & NS \\
\hline Siesto et al. ${ }^{22}$ & Lscp $\geq 65 / \leq 65$ & $\mathrm{~N} / \mathrm{P}$ & $\mathrm{N} / \mathrm{P}$ & $18 / 18$ & NS \\
\hline Perrone et al. ${ }^{41}$ & Lscp $\geq 70 /<70$ & $\mathrm{~N} / \mathrm{P}$ & $\mathrm{N} / \mathrm{P}$ & $15.2 / 18.6$ & NS \\
\hline Vaknin et al. ${ }^{35}$ & $\mathrm{Ltm} \geq 70 /<70$ & $\mathrm{~N} / \mathrm{P}$ & $\mathrm{N} / \mathrm{P}$ & $4 / 10.4$ & $<0.001$ \\
\hline Lachance et al. ${ }^{19}$ & $\mathrm{Ltm} \geq 65 /<65$ & $\mathrm{~N} / \mathrm{P}$ & $\mathrm{N} / \mathrm{P}$ & $17.9 / 14.7$ & NS \\
\hline Vaknin et al. ${ }^{24}$ & Rob $\geq 70 /<70$ & $\mathrm{~N} / \mathrm{P}$ & $\mathrm{N} / \mathrm{P}$ & $11 / 13$ & 0.006 \\
\hline Lowe et al. ${ }^{43}$ & Rob $\geq 80 /<80$ & $\mathrm{~N} / \mathrm{P}$ & $\mathrm{N} / \mathrm{P}$ & $16 / 16$ & NS \\
\hline Zeng et al. ${ }^{23}$ & Rob $\geq 80 / 80$ to $70 /<70$ & $\mathrm{~N} / \mathrm{P}$ & $\mathrm{N} / \mathrm{P}$ & $9.7 / 10.3 / 11.8$ & NS \\
\hline Lavoue et al. ${ }^{44}$ & Rob $/ \mathrm{Ltm} \geq 70$ & 8.8/8.4 & $\mathrm{N} / \mathrm{P}$ & $10.3 / 9.7$ & NS \\
\hline
\end{tabular}

Table 5: Mean number of lymph nodes removed in studies looking at surgical management of endometrial cancer in elderly women 